[Preprint; final version published as: Noonan, D. S. (2013). How US cultural districts reshape neighbourhoods. Cultural Trends, 22(3-4), 203-212. doi:10.1080/09548963.2013.817652]

\title{
How U.S. Cultural Districts REShape NeIGHbOURHOODS
}

\author{
Douglas S. Noonan
}

Associate Professor

Director of Research

School of Public and Environmental Affairs (SPEA)

Indiana University Public Policy Institute

Indiana University-Purdue University Indianapolis

\begin{abstract}
Cultural districts are an increasingly popular and important element of both urban and cultural experiences in the United States. Cultural districts get invoked as a tool for revitalising neighbourhoods and regions, cultivating arts and cultural resources, and other goals. This article briefly describes the phenomenon of cultural districts in the United States, reviews some claims made about their impacts, and provides evidence of districts' effects. Neighourhood-level statistical analyses identify socioeconomic trends in neighbourhoods affected by districts. The results reflect the heterogeneity in cultural districts and in cities' experiences with them. The findings inform policies supporting creative placemaking in general and cultural districts as a system.
\end{abstract}




\section{How U.S. Cultural Districts Reshape Neighbourhoods}

Increasingly popular and important in urban and cultural experiences, Cultural districts serve purposes like revitalising communities, sustainable economic development, and cultivating arts and cultural resources (Brooks and Kushner 2001). The wave of cultural districts has kept far ahead of objective analysis of their effectiveness and sustainability. This article reviews some claims made about districts' impacts and provides more comprehensive and robust evidence of whether cultural districts tend to live up to the hype. In particular, demographic trends of neighbourhood in and near districts are compared before and after districts' formation. The results are mixed, like cities' experiences with districts. The findings point to consistent relationships in some cases (e.g., income and employment growth) and, importantly, the absence of relationships in others (e.g., gentrification). The analysis also highlights key challenges for future empirical research.

\section{Introduction to Cultural Districts in the United States}

Cultural districts are formally designated or labeled areas with high concentrations of cultural activities and institutions (Frost-Kumpf 2001). These districts are not exclusive to arts (i.e., other land uses occur), and what constitutes "culture" can vary widely across and within districts. . (Historic districts primarily limited to preserving historic character are not counted as cultural districts.) They are not just clusters of galleries or theatres, but are areas with defined boundaries that are formally labeled as such a district. These districts might get their labels and boundaries from local government, business groups, or elsewhere. Naturally, some cultural districts begin "organically" as a cluster of arts organizations and activities that lead to recognition and the subsequent formal designation of the district (Stern and Seifert 2010). On the other hand, a few 
begin as areas with no ongoing arts or cultural presence but use district designation to attract such a cluster.

Cultural districts manifest differently around the world. While I consider only the US experience here, Santagata (2002) provides an excellent general introduction in the global phenomenon. Cultural districts overlap and are embedded within broader notions of "cultural clusters" and "creative placemaking" discussed at length elsewhere (e.g., Stern and Seifert 2010, Markusen and Gadwa 2010b). This narrower scope - US cultural districts - is empirically tractable while representing a substantial cultural trend in its own right. Districts can cultivate activities at three levels: primary cultural facilities and producers (e.g., museums, theatres, studios), secondary producers (e.g., arts and crafts workshops, music and movie studios), and complementary producers (e.g., gift shops, restaurants, hotels) (Santagata 2002). Which levels are favored varies across districts.

The mechanisms supporting cultural districts vary widely (Brooks and Kushner 2001). They range from largely private efforts (e.g., local business coordinating marketing) to passive government support (e.g., incorporating districts in plans, special zoning) to more active (e.g., infrastructure investments, staffing, grants). A few districts are little more than officially recognised by the city along with a website and a couple street signs. Many states now enable local governments to create districts, and a handful offer significant tax incentives. The National Endowment for the Arts supports "Creative Placemaking” through its Our Town grants in over 80 communities nationwide.

Stakeholders for creating cultural districts can include artists, (non-arts) businesses, local city governments, nonprofits, neighbourhood associations, preservationists, and more. At some point, a community can organise to capture, protect, and cultivate the shared value in local cultural production (Santagata 2002). Successful arts districts exhibit robust coalitions that span traditional 
boundaries, as governments, nonprofits, and business communities collaborate in its operation (Brooks and Kushner 2001).

Frost-Kumpf (2001) details the long history of cultural districts in the United States. The term "cultural districts" or "cultural quarters" in its modern meaning dates back only the early 1980s (Montgomery 2003). Recent decades have brought new interest in cultural districts as a local economic development tool. The number of districts tripled from 40 in 1995 (Frost-Kumpf 2001) to 127 in 2008 (NASAA 2008). Cities and donors alike invested heavily in cultural districts in the past few decades. While the largest cities have significant agglomerations of cultural industries and districts of their own, cultural districts have spread to even small towns.

Cultural districts represent a high-profile and rapidly growing trend in arts and cultural policy across the nation. Cultural districts' ability to connect political and economic interests around cultural themes partly explains the extent of their popularity (Strom 2002). Often "placemaking" or "branding” via districts seeks to attract outside resources (tourism, new businesses and residents, government transfers) or develop existing local strengths (lest they migrate to elsewhere). As public investments, they are place-based policies seeking to cultivate a cultural "scene" and fix it in a particular location. This marks a departure from conventional forms of public support for arts that aim to boost cultural production regardless of location.

The cultural districts movement in the U.S. has a close connection to an academic and advocacy literature on the "creative economy" (e.g., Florida 2002, Americans for the Arts 2012, Markusen 2006a). The promise of the "creative class" gained traction and held significant appeal to address regional and urban economic development concerns, and many localities sought to develop their own creative economy. Yet the evidence supporting this promise is thin at best. Even while scholars usefully debate the "creative class" arguments (e.g., Markusen 2006b, Tepper 2002), the more specific question of "what are cultural districts' impacts?" has far more speculation and hope 
than empirical evidence. This was certainly true when Lim (1993) lamented hype from advocates, later when Evans (2005) observed only limited evidence on impacts, and still when Markusen and Gadwa (2010a) critiqued the existing evidence. Evans argues that "attention to the high-cost and high-profile culture-led regeneration projects is in inverse proportion to the strength and quality of evidence of their regenerative effects" (2005, p.960). In light of ongoing investment in cultural districts, the analysis here provides the first tests of many impacts using a systematic, quantitative approach applied to a national sample of cultural districts. Such an approach is still sorely lacking in the literature (Brooks and Kushner 2001, Markusen and Gadwa 2010a).

The approach here abstracts away from the rich details of particular districts in order to assess cultural districts as a broader phenomenon. Of course, every particular district has its own unique story and objectives. Yet looking across many cultural districts improves our understanding of which claims about districts' impacts are generalisable and why some districts perform differently than others, and it might help policymakers and arts advocates be more selective in where they invest scarce resources to promote the cultural sector and other goals. This approach complements the richer case studies more commonly performed.

There are many claims about the benefits of arts development in general and cultural districts in particular. Frost-Kumpf (2001) lists several, such as increases in employment, population, property values, and education levels. Markusen and Gadwa (2010b) cite creative placemaking's positive impacts on jobs, income, and vacancies. Criticisms and undesirable impacts are infrequently mentioned in the literature (Strom 2002). Gentrification and displacing residents and tenants are perhaps the primary concerns in establishing cultural districts (NASAA 2008, Markusen and Gadwa 2010b). Cultural districts' sustainability is another concern, in light of the recent severe recession. Other drawbacks include the opportunity costs of supporting the 
concentrated investment. Displacing and disrupting more "organic" or decentralised cultural production and consumption may create "losers" in the process.

\section{Empirical approaches}

This analysis sheds empirical light on the US cultural district phenomenon, the neighbourhoods nearby, and how districts influenced their demographic and economic trends. The main hypotheses to test follow directly from claims by scholars and boosters discussing cultural districts. They include:

\section{Hypothesized impact}

1. Districts increase income

2. Districts reduce unemployment, bring jobs to the area

3. Districts retain residents, stabilise neighbourhoods

4. Districts increase local population, change the demographic mix

5. Districts increase property values

6. Districts attract more educated people

\section{Indicator(s) used}

Income - log of median household annual income

Poverty - percent of population under $150 \%$ of poverty line Employment - percent of families with working adults TravelTime - average commute time in minutes

Renters - percent of households renting

Stayers - percent of population in same residence $5+$ years PopDensity - log of population density White - percent of population that is White Children - percent of families with children in the home PropValues - log of median housing price College - percent of adults with college degrees

Along with each claim or expected impact are one or more indicators in the righthand column.

The empirical analysis proceeds in two phases in order to measure impacts. The first phase is simply to assess the average demographic conditions and trends inside and outside of districts. Basic t-tests identify significant differences between cities and neighbourhoods with and without districts. This highlights the importance of separating causality from mere correlation in understanding cultural districts' impact. When district formation is not exogenous or randomly assigned, causal inferences can be problematic. Even if districts cause neighbourhood change, perhaps declining (or ascendant) neighbourhoods attract cultural districts in the first place. 
The second phase refines the neighbourhood comparison to leverage within-city variation in neighbourhood trajectory and controls for additional observed and unobserved factors. In each city, three groups of neighbourhoods are identified: all block groups that contain cultural districts, block groups adjacent to those host block groups, and all remaining block groups in the district's county. The first group of neighbourhoods should feel cultural districts' effects most strongly. As adjacent neighbourhoods are most similar to host neighbourhoods, comparing them makes for a relatively clean test of the hypothesis that districts significantly alter neighbourhood dynamics, especially if districts' boundaries contain their influence. ${ }^{1}$ District impacts might extend into adjacent areas due to congestion, higher prices or other forces. I allow for this by using the third group, the rest of the county, as a comparison for both host and adjacent neighbourhoods. ${ }^{2}$

Regression models estimate the effect of being in or near cultural districts with a neighbourhood level of analysis that allows for a "difference-in-difference"-style estimation of the effects. More than just differences over time (the first difference or pre- vs. post-district, as Brooks and Kushner (2001) use), the neighbourhood-level analysis sharpen the analysis by also examining differences in trends over space (the second difference or inside vs. outside districts). This approach soaks up many of the unobserved factors that might bias the impact estimates. Using a larger dataset, multivariate models, and finer-grained spatial analysis of district impacts directly addresses a high-priority research agenda item of Markusen and Gadwa (2010a): testing the causal links. It is a big step in the right direction, albeit just a step.

Several datasets are combined for the analysis. First, an inventory of cultural districts was assembled. This inventory is largely based on Frost-Kumpfs $(1998,2000)$ lists, amended to include

\footnotetext{
${ }^{1}$ How district effects decay over space merits further research. My straightforward approach is common in policy evaluations like this, but impacts may spatially diffuse in different patterns.

2 Although district effects are expected to fade or vanish with distance (leaving estimated effects for adjacent areas smaller than for host areas, in absolute value), the empirical approach here allows for other possibilities, such as effects on adjacent areas being in a different direction than in host areas.
} 
some newer districts and to remove several that could not be verified. Frost-Kumpfs inventory holds great appeal because of its completeness and because its timing just prior to the 2000 Census helps establishing clear benchmarks in the socioeconomic data. Her list of cultural districts included existing districts as well as districts that were merely planned or proposed. Several never progressed beyond the proposal stage or have since vanished (e.g., Decorah's cultural district). The search to recreate and map Frost-Kumpfs inventory unearthed several new districts in the cities listed. These are either districts that formed after 2000 (e.g., Providence's West Side Arts District) or were in addition to the one district listed (e.g., Washington DC's Uptown and Downtown Arts districts).

Some of the districts that she identified could not be found, at least not by the standard that they are formally declared as cultural (broadly defined) regions and recognised as such. The omission of these districts ultimately weeds out the most minor or dubious cases as well as ones that actually disappeared. There is a risk of failure in these kinds of efforts (Santagata 2002). Basing the inventory on Frost-Kumpf's also excludes several new cultural districts and the proliferation of state-designated districts, a new phase in the evolution of cultural districting. ${ }^{3}$ Thus, I interpret estimates as impacts of the most notable and sustained districts; including failed or unnoted districts likely reduces those estimates.

The sample of 99 U.S. urban cultural districts exhibits great variety. Their average size is roughly $1 \mathrm{~km}^{2}$, though they range from very small to $4.5 \mathrm{~km}^{2}$. The average year formed for districts in the sample is 1995, although some are much older. Roughly a third of the districts were formed in the 1990s and another third in the 2000s. Clearly this is an emerging phenomenon. Host cities range from very small (e.g., Lafayette, CO) to very large (e.g., New York City).

\footnotetext{
${ }^{3}$ Recent batches include 63 Louisiana districts (http://www.crt.state.la.us/culturaldistricts/) and 35 Iowa districts (http://www.iowahistory.org/historic-preservation/cultural districts/list-of-certified-districts.html ).
} 
This novel dataset of cultural districts is joined spatially with neighbourhood census data for 1980-2000, converted to time-consistent geographic units by GeoLytics, Inc. ${ }^{4}$ The socioeconomic indicators from the census are measured at the block-group level, an areal unit smaller than census tracts (average population is 4,000 ) whose boundaries are drawn with local input to match local perceptions of "neighbourhood" (Coulton et al. 2004).

\section{Analyses and results}

To start, I compare demographics from the 1980 Census for cities hosting districts (in 1980 or later) with cities lacking districts. As largely a post-1980 phenomenon, these snapshots inform comparisons of baselines between host and non-host cities. The unit of measure here is the Censusdesignated place, which corresponds to municipalities. The means of demographic indicators for the two groups, future hosts and non-hosts, are compared via a t-test (unequal variances). Table 1 indicates that cities that would formally designate cultural districts differ from other cities in several prominent dimensions. They are much larger on average than other typical cities. Their income is much less and fewer residents raise children. Housing prices do not appear to differ.

\section{TABLE 1: Demographics of Places Hosting and Not Hosting Districts}

\begin{tabular}{lllllc}
\hline & \multicolumn{2}{c}{ Hosts a district } & \multicolumn{2}{c}{ Not host a district } & significant \\
\cline { 2 - 6 } nean & std.dev & mean & std.dev & difference \\
\cline { 2 - 6 } median housing value & 99255.97 & 163859.60 & 4648.19 & 15114.44 & $* * *$ \\
median household income & 54850.72 & 22345.79 & 53119.57 & 27848.48 & \\
percent of households with children & 16560.71 & 3472.55 & 19045.42 & 6794.69 & $* * *$ \\
\hline
\end{tabular}

$*, * *, * * *$ indicate significance at the $0.10,0.05,0.01$ level, respectively.

City means in Table 1 limit the analysis to comparing only across cities. It overlooks withincity variation. Aggregating to the municipality level can hide important dynamics and diversity at the

\footnotetext{
4 This document contains demographic data from GeoLytics, E. Brunswick, NJ. This proprietary dataset projects historical decennial Census data onto time-invariant geographic boundaries, which is essential for analysing local trends spanning more than 10 years, because Census boundaries frequently change.
} 
neighbourhood level. Table 2 shows how socio-economic factors differ between neighbourhoods that host (or will host) cultural districts and those that never have. (The sample of control neighbourhoods is restricted to counties that have cultural districts. Roughly 660 block-groups contain cultural districts, and approximately 50,000 do not.) Like Table 1, 1980 measures allow comparisons of baseline or preexisting conditions. Also, measures of trends from $1980-1990$ show how the group of host neighbourhoods have changed relative to their non-hosting counterparts.

Table 1 shows that host cities differ from non-host cities, and Table 2 evidences how host neighbourhoods differ from the rest of urban counties. In 1980, host neighbourhoods were poorer, lower rent, more dense, less White, and filled with renters less apt to stay in the same house for long. In short, it is a comparison not unlike central core to suburbs. ${ }^{5}$

TABLE 2: Demographics of Neighbourhoods Hosting and Not Hosting Districts

\begin{tabular}{|c|c|c|c|c|c|c|}
\hline & $\begin{array}{l}\text { Hosts a district } \\
1980 \text { mean }\end{array}$ & $\begin{array}{l}\text { Not host a } \\
\text { district } \\
1980 \text { mean }\end{array}$ & sig. diff. & $\begin{array}{c}\text { Hosts a district } \\
1990-2000 \\
\text { mean }\end{array}$ & $\begin{array}{l}\text { Not host a } \\
\text { district } \\
1990-2000 \\
\text { mean }\end{array}$ & sig. diff. \\
\hline PropV Vlue & 10.52 & 10.83 & $* * *$ & 0.40 & 0.29 & \\
\hline Income & 9.17 & 9.77 & $* * *$ & 0.37 & 0.31 & \\
\hline PopDensity & 8.71 & 8.21 & $* * *$ & 0.01 & 0.08 & $* * *$ \\
\hline TravelTime & 22.48 & 26.42 & $* * *$ & 1.93 & 2.10 & \\
\hline Employment & 0.77 & 0.87 & $* * *$ & 0.04 & 0.01 & $* * *$ \\
\hline Poverty & 0.40 & 0.20 & $* * *$ & -0.03 & 0.01 & $* * *$ \\
\hline White & 0.63 & 0.73 & $* * *$ & -0.07 & -0.09 & \\
\hline Children & 0.17 & 0.25 & $* * *$ & -0.01 & 0.01 & \\
\hline College & 0.15 & 0.16 & $* * *$ & 0.08 & 0.05 & $* * *$ \\
\hline Renters & 0.72 & 0.38 & $* * *$ & -0.01 & 0.00 & \\
\hline Stayers & 0.41 & 0.48 & $* * *$ & 0.01 & 0.02 & \\
\hline
\end{tabular}

$*, * *, * * *$ indicate significance at the $0.10,0.05,0.01$ level, respectively. See section 2 for variable definitions.

Table 2 also offers us a first glimpse at some tests of the hypothesized impacts of cultural districts. The righthand side of Table 2 depicts the average changes in the indicators from 1990 to 2000 for the two groups. Notably, even with the same statistical power of 50,000-plus observations,

\footnotetext{
${ }^{5}$ Neighbourhoods with districts are not just different from the rest of the city - they also differ in important ways from the adjacent neighbourhoods. Adjacent areas have significantly higher (1980) incomes, employment rates, youth populations, and shares of long-term residents than district neighbourhoods. Adjacent neighbourhoods have significantly lower densities, poverty rates, and rentership rates as well.
} 
only a handful of the indicators show a different dynamic for hosts and non-hosts. Relative to other urban county neighbourhoods, block groups with districts got more jobs, less poverty, and more educated residents - all consistent with expectations. The lack of support for the other hypotheses is more disconcerting.

\section{Neighbourhood-level regressions}

The next set of regression models provides much more robust approaches to identifying the impacts of cultural districts. The fixed-effects regressions offer several advantages over merely comparing means. First, the fixed-effects allow for each urban area to have its own county-wide trend. Second, they include another group of neighbourhoods, those nearby but not inside district boundaries ("adjacents"). And third, the extended models allow for controls over the previous trends in neighbourhoods that might explain why some neighbourhoods received a district and others did not. By taking into account Brooks and Kushner's (2001) concerns about preexisting trends, these models present the most robust evidence of causal impacts of cultural districts. Further, examining the "adjacent" neighbourhoods sheds light on some obvious theorised relationships: namely that district effects fade with distance from the cluster (i.e., a weaker effect for adjacent neighbourhoods than neighbourhoods containing districts) and that districts impact adjacent neighbourhoods through displacement and gentrification.

The models estimated for Table 3 start with the linear form:

$$
y_{t}=\alpha+\tau T+\beta D_{t}+\rho y_{t-1}+\mu+\delta_{t}+\varepsilon_{t}
$$

The dependent variable $y$ depends on a linear time trend $T$, district status $D$, previous values of $y$, a county-specific time-invariant factor $\mu$, a county-specific time-varying factor $\delta$, and an error term. The lagged $y$ is a vector that includes the full set of indicators to better establish the previous time trends for a neighbourhood. $D$ contains both host and adjacent status. Taking the difference between two time periods, 2000 and 1990, yields: 


$$
\Delta y_{t}=\tau+\beta \Delta D_{t}+\rho \Delta y_{t-1}+\Delta \delta+\Delta \varepsilon_{t}
$$

We can recover the parameters of interest, $\beta$, by estimating the equation in first differences. Note that the $\Delta \delta$ term is a county-specific time trend, the county-specific level effect $\mu$ has been differenced out. Equation (1) can be estimated in differences with county-level fixed effects. For each of 11 different dependent variables, Table 3 shows the estimated coefficients $\beta$ for whether the neighbourhood received a district during the 1990s and whether it was adjacent to a neighbourhood that became a host during the 1990s. The first row of results for each dependent variable omits the past trend vectors, assuming $\rho=0$. The model for the second row controls for past trends but suppresses those coefficients for space reasons. Significant test statistics for the $\beta$ 's indicates that the group, hosts or adjacents, has a significantly different trend in $y$ relative to the other neighbourhoods in urban counties. Again, that difference is conditional on county-specific time trends and, for the second row results, past socioeconomic trends. Whether the $\beta$ for hosts differs from the $\beta$ for adjacents is tested. The results of that test appear in the rightmost column.

Several broad conclusions follow from Table 3. First, cultural districts appear to have significant impacts on property values, income, employment, and migration. The evidence of impacts on poverty, education, and families with kids is weaker. Districts appear to boost property values, incomes, employment, and turnover in the vicinity. Interestingly, improving employment rates without reducing commute times does not suggest that residents are being employed more in and around the district. Likely, newcomers still work outside of the area. Second, controlling for past trends can affect the estimates of impact, although the influence is complex. Property value growth rates are $8 \%$ higher in host neighbourhoods. When that effect is conditional on past trends, however, the growth rates are almost 10\% higher. For income, controlling for past trends weakens the effect. Third, cultural districts' impacts appear no different in host and adjacent neighbourhoods. The marginally significant difference for Children is very small in magnitude 
anyway. Fourth, the null effect on population and positive effects on turnover suggest some

displacement of locals (who tend to be poorer and less employed). Displacement along with higher property prices is disconcerting in light of districts' high rentership rates.

TABLE 3: OLS REGRESSIONS EXPLAINING SOCIO-ECONOMIC TRENDS

\begin{tabular}{|c|c|c|c|c|c|c|c|}
\hline \multirow[b]{2}{*}{ dependent variable } & \multirow[b]{2}{*}{$\mathbf{N}$} & \multirow[b]{2}{*}{$\begin{array}{l}\text { Past } \\
\text { trends?a }\end{array}$} & \multicolumn{2}{|c|}{$\begin{array}{l}\text { Hosts a 1990s } \\
\text { District }\end{array}$} & \multicolumn{2}{|c|}{$\begin{array}{l}\text { Adjacent to a 1990s } \\
\text { District host }\end{array}$} & \multirow[b]{2}{*}{$\begin{array}{l}\text { sig. } \\
\text { diff. }\end{array}$} \\
\hline & & & coef. & $\begin{array}{l}\text { std. } \\
\text { error }\end{array}$ & coef. & $\begin{array}{l}\text { std. } \\
\text { error }\end{array}$ & \\
\hline PropValues $2000-1990$ & 22212 & $\mathrm{~N}$ & 0.077 & 0.05 & $0.045^{*}$ & 0.02 & \\
\hline PropValues $2000-1990$ & 22178 & $\mathrm{Y}$ & $0.093^{* *}$ & 0.04 & $0.073^{* *}$ & 0.03 & \\
\hline Income $2000-1990$ & 23031 & $\mathrm{~N}$ & $0.077 * *$ & 0.03 & $0.049 * * *$ & 0.02 & \\
\hline Income $2000-1990$ & 22438 & Y & $0.054 * *$ & 0.03 & $0.050^{* * *}$ & 0.02 & \\
\hline PopDensity2000-1990 & 23094 & $\mathrm{~N}$ & -0.030 & 0.03 & $-0.064 * *$ & 0.03 & \\
\hline PopDensity $2000-1990$ & 22446 & $\mathrm{Y}$ & -0.015 & 0.03 & -0.027 & 0.02 & \\
\hline TravelTime $2000-1990$ & 23011 & $\mathrm{~N}$ & 0.080 & 0.61 & 0.307 & 0.29 & \\
\hline TravelTime $2000-1990$ & 22430 & Y & 0.327 & 0.71 & 0.262 & 0.30 & \\
\hline Employment $2000-1990$ & 22971 & $\mathrm{~N}$ & $0.038^{* * *}$ & 0.01 & $0.033^{* * *}$ & 0.01 & \\
\hline Employment $2000-1990$ & 22427 & $\mathrm{Y}$ & $0.044 * * *$ & 0.01 & $0.035^{* * *}$ & 0.01 & \\
\hline Poverty2000-1990 & 23052 & $\mathrm{~N}$ & $-0.041 * *$ & 0.01 & $-0.018^{* *}$ & 0.01 & * \\
\hline Poverty2000-1990 & 22439 & Y & $-0.023^{*}$ & 0.01 & -0.012 & 0.01 & \\
\hline White 2000-1990 & 23095 & $\mathrm{~N}$ & 0.022 & 0.02 & 0.014 & 0.01 & \\
\hline White $2000-1990$ & 22446 & $\mathrm{Y}$ & 0.016 & 0.01 & 0.005 & 0.01 & \\
\hline Children $_{2000-1990}$ & 23095 & $\mathrm{~N}$ & $-0.012^{*}$ & 0.01 & -0.002 & 0.00 & $*$ \\
\hline Children $_{2000-1990}$ & 22446 & $\mathrm{Y}$ & -0.003 & 0.01 & $0.009 * *$ & 0.00 & * \\
\hline College $_{2000-1990}$ & 23084 & $\mathrm{~N}$ & $0.024^{*}$ & 0.01 & 0.010 & 0.01 & \\
\hline College $2000-1990$ & 22443 & Y & $0.025^{* *}$ & 0.01 & 0.011 & 0.01 & \\
\hline Renter $2000-1990$ & 23029 & $\mathrm{~N}$ & -0.001 & 0.01 & 0.002 & 0.00 & \\
\hline Renter $_{2000-1990}$ & 22438 & $\mathrm{Y}$ & 0.008 & 0.01 & 0.006 & 0.00 & \\
\hline Stayer $_{2000-1990}$ & 23095 & $\mathrm{~N}$ & $-0.024 * * *$ & 0.01 & $-0.021 * * *$ & 0.01 & \\
\hline Stayer $_{2000-1990}$ & 22446 & $\mathrm{Y}$ & $-0.027 * * *$ & 0.01 & $-0.028 * * *$ & 0.01 & \\
\hline
\end{tabular}

$*, * *, * * *$ indicate significance at the $0.10,0.05,0.01$ level, respectively.

All models are computed with county-level fixed effects and robust errors clustered by county group.

a "Past trends?" indicates whether the regression includes trend variables measuring changes from 1980 to 1990. The set of control variables include the lagged differences in each of the 11 dependent variables used in this table.

\section{Discussion and Conclusion}

Cultural districts have captured a great deal of attention and investment in the U.S. urban renewal and arts advocacy arenas. The list of cultural districts keeps growing and changing. These 
districts represent a motley collection of developments and experiences despite their commonality of their concentrating cultural activities in recognised and demarcated mixed-use areas. As is common for fashionable policy tools, efforts at systematic evaluation lag behind. The popularity of cultural districts does provide a great many data points and rich variation to study. We can learn much from this experimentation, and we need to learn as much from the failures as from the successes. Several districts have already vanished or keep such a low profile that they are functionally useless. For example, Frost-Kumpf (1998) profiled the Tucson Arts District Partnership, lauding its stellar impacts on job, sales, and tax revenue creation. Yet only a few years later that District was defunct.

That outcomes should vary widely just as cultural districts themselves differ so greatly should not be surprising. The diverse collection of districts ranges from fully private to largely public, from little more than naming a neighbourhood to wholesale redevelopment of a city section, from consumption-based to production-based, from merely recognising the cluster that had already organically formed to constructing a cluster de novo, etc. Yet even diverse paths may lead to similar destinations. The analysis here adds new evidence on the impacts of cultural districting in general. I find little evidence to support the idea that forming cultural districts has consistently significant effects on population, education, race, families with children, or distance to employment. The analysis does reveal significant positive effects of district formation on property values, employment, and income. This evidence is not generally robust to more flexible statistical approaches that control for cities' own particular trajectories, however. A selection problem plagues this area, and research claiming that districts have a causal impact must be able to establish a credible counterfactual (i.e., what neighbourhoods would have experienced in the absence of district formation). There is enough evidence of displacement and gentrification to warrant additional research.

Again, this analysis focuses on the average impacts of US cultural districts - specifically those established in the 1990s. I identify the average impacts of ostensibly "successful" cultural 
districts (in that they were created and survived to be in my dataset). The results reported here cannot indicate whether any particular district is a success or failure, no matter its goals. The critical question of what makes for successful arts districts simply cannot be answered satisfactorily without understanding why some districts fail to progress past the proposal stage or why some cities do not even entertain the proposal. Otherwise, generalising from successful cases might inspire similar district designs in other cities, as "every town should have one" (Evans 2005). More and better data on additional districts and urban centres, and more sophisticated models, are needed to assess whether particular attributes of cities or districts engender success. Research like Montgomery (2003) offers some theory and case studies to test for elements that make districts successful, but case study approaches are limited in their generalisability. Given the enormous attention to, popularity of, and investment in cultural districts, still more effort is needed to systematically collect more data and carefully analyse American cities' experiences with cultural districts. Data on failed and successful districts and better models, which account for different types of districts and local context, might further unpack these results and enrich our understanding of the phenomenon.

Cultural districts do tend to consistently influence neighbourhood dynamics, although not always as expected. As more cities develop districts, they attract investments from nonprofits, volunteers, businesses, and governments. A better understanding of how these projects perform is paramount for stakeholders of many stripes. These results are another step along that journey. 


\section{References:}

Americans for the Arts (2012). Arts and Economic Prosperity IV. Washington, DC: Americans for the Arts.

Brooks, Arthur C. and Roland J. Kushner (2001). "Cultural districts and urban development." International Journal of Arts Management 3(2): 4-15.

Coulton, C., T. Cook, and M. Irwin (2004). “Aggregation Issues in Neighbourhood Research: A Comparison of Several Levels of Census Geography and Resident Defined Neighbourhoods.” APPAM Fall Research Conference, Atlanta, GA.

Evans, Graeme (2005) “Measure for measure: Evaluating the evidence of culture's contribution to regeneration.” Urban Studies 42(5/6): 959-983.

Florida, Richard (2002) The Rise of the Creative Class, New York, NY: Basic Books.

Frost-Kumpf, Hilary Anne (1998) Cultural Districts: The Arts As a Strategy for Revitalizing Our Cities Washington, DC: Americans for the Arts.

Frost-Kumpf, Hilary Anne (2001) Cultural Districts: Arts Management and Urban Redevelopment. Dissertation in Geography at Penn State University.

Lim, Hoe (1993) "Cultural strategies for revitalizing the city: a review and evaluation." Regional Studies 27(6): 589-595.

Markusen, A. and Gadwa, A. (2010a) "Arts and Culture in Urban or Regional Planning: A Review and Research Agenda." Journal of Planning Education and Research 29(3): 379-391.

Markusen, A. and Gadwa, A. (2010b) Creative Placemaking. Washington, DC: Mayors' Institute on City Design and the National Endowment for the Arts.

Markusen, Ann (2006a) "Cultural Planning and the Creative City." Paper presented at the annual American Collegiate Schools of Planning meetings, Fort Worth, Texas, November 12. 
Markusen, Ann (2006b) “Urban Development and the Politics of a Creative Class: Evidence from the Study of Artists." Environment and Planning A 38: 1921-1940.

Markusen, Ann, Gregory H. Wassall, Douglas DeNatale, and Randy Cohen (2008) "Defining the Creative Economy: Industry and Occupational Approaches.” Economic Development Quarterly 22(1): 24-45.

Montgomery, John (2003) “Cultural quarters as mechanisms for urban regeneration. Part I: Conceptualising cultural quarters.” Planning, Practice \& Research 18(4): 293-306.

NASAA (National Association of State Arts Agencies) (2008) "State Cultural Districts." National Association of State Arts Agencies: State Policy Briefs. http://www.nasaaarts.org/Research/Key-Topics/Creative-Economic-

Development/StateCulturalDistrictsPolicyBrief.pdf

Santagata, Walter (2002) “Cultural Districts, Propoerty Rights and Sustainable Economic Growth.” International Journal of Urban and Regional Reesarch 26(1): 9-23.

Stern, M. J. and Seifert, S. C. (2010) "Cultural Clusters: The Implications of Cultural Assets Agglomeration for Neighbourhood Revitalization." Journal of Planning Education and Research 29(3): 262-279.

Strom, E. (2002) “Converting Pork in to Porcelain: Cultural Institutions and Downtown Development." Urban Affairs Review 38(1): 3-21.

Tepper, Steven Jay (2002) “Creative Assets and the Changing Economy." Journal of Arts Management, Law, and Society 32(2): 159-168. 